\title{
Epilepsiezorg in Aruba
}

Aruba kampt al jaren met een tekort aan medisch specialisten. In het verleden was er een vaste groep neurologen die vanuit Nederland het chronisch tekort aan neurologen op het eiland opvulden. Zo is het ook bij mij begonnen; sinds 2012 neem ik als neuroloog jaarlijks twee tot drie weken waar op Aruba. Nu ben ik nog de enige neuroloog met speciale aandacht voor de epilepsiezorg op Aruba.

In 2012 was er één vaste neuroloog op Aruba. De overige plekken werden door waarnemers opgevuld. De tweede neuroloog, Jaime Falconi, was kort daarvoor aangesteld als medisch directeur van het ziekenhuis op het eiland, het Horacio Oduber Hospital (HOH) (figuur I). Falconi had epilepsie als aandachtsgebied. Patiënten met complexe epilepsie werden vooral door hem gezien. Zo had hij ook enkele patiënten met een nervus vagus stimulator (NVS) onder zijn hoede. De patiënten werden nadat Falconi aantrad in zijn nieuwe functie steeds door verschillende waarnemers behandeld. De patiënten met een NVS werden weliswaar poliklinisch behandeld, maar zonder controle van de NVS. Op verzoek van Falconi heb ik vanaf 2012 de patiënten met een NVS gecontroleerd (gelukkig kon ik het instelapparaat van de NVS nog ergens op de polikliniek terugvinden). Dit was het begin van mijn epilepsiepoli op Aruba. De patiënten met een NVS probeerde ik op regelmatige basis te controleren en bij te stellen, en, in het geval van een lege batterij, probeerde ik een verwijzing te regelen naar Colombia voor vervanging. Geleidelijk aan kreeg ik meer patiënten in behandeling met een complexe epilepsie of met verdenking op epilepsie. De vaste patiën- tenpopulatie die ik nu behandel is gegroeid tot ongeveer 75 patiënten per jaar.

\section{Complexe diagnostiek}

Het $\mathrm{HOH}$ heeft een beperkte afdeling Klinische NeuroFysiologie (KNF) met één vaste laborante en de mogelijkheid om onder andere routine-EEG's te verrichten. Voor complexere diagnostiek, zoals EEG-videomonitoring in het kader van differentiaaldiagnostiek en onderzoek naar de mogelijkheden van epilepsiechirurgie worden patiënten verwezen naar Colombia (vooral naar Bogota en Cali). Patiënten met een duidelijk klinisch beeld van een temporaalkwabepilepsie en met beeldvorming en EEG-videomonitoring die daar goed bij passen, worden in Colombia adequaat geopereerd met een vergelijkbaar postoperatieve uitkomst als de centra in Nederland. Wel bleek de voorlichting, begeleiding en nazorg vanuit Colombia op zijn zachtst gezegd gebrekkig te zijn. In Aruba ontbreekt de expertise om patiënten goed te counselen en voor en na een operatie te begeleiden. Een betere begeleiding van deze patiënten betekende in eerste instantie vooral straf onderhandelen met AZV, de enige zorgverzekeraar in Aruba en

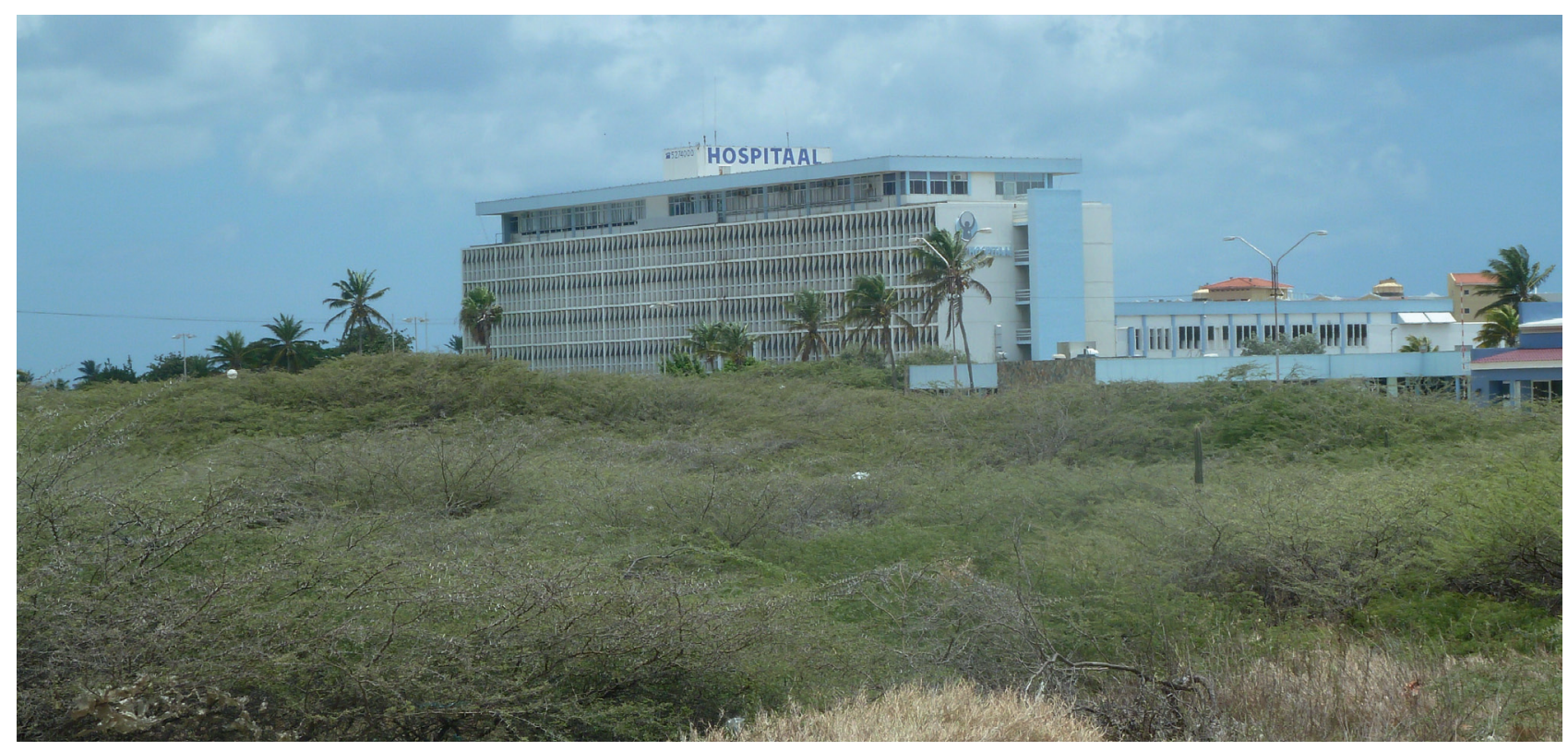

Figuur 1 het (oude) Horacio Oduber Hospital in Oranjestad. 
dus een machtige onderhandelingspartij, waarbij ik vooral in de beginperiode geregeld nul op het rekest kreeg wanneer ik een patiënt wilde verwijzen naar Nederland. Een belangrijke reden hievoor is dat voor bepaalde programma's, diagnostisch en/of therapeutisch, Colombia veel goedkoper is dan Nederland. Uiteindelijk is het voor enkele patiënten wel gelukt om een goedkeuring te krijgen voor verwijzing naar Nederland. In het navolgende hiervan een voorbeeld.

\section{Casus}

In januari 2019 werd ik door de kinderarts op Aruba gevraagd mee te kijken bij een meisje van bijna vier jaar oud dat zeer frequent aanvallen had en voor wie anti-epileptische medicatie geen oplossing bood. Ze was in $2018 \mathrm{al}$ tweemaal in Colombia geweest voor diagnostiek en behandeling, maar dit had weinig uitgehaald. Er werd op Aruba een MRI gemaakt, die geen uitsluitsel gaf, en een routineEEG. Het routine-EEG vertoonde veel ictale ontladingen, vanuit links centropariëtaal. Het verzoek om haar in Nederland te behandelen werd door AZV afgewezen, ze werd verwezen naar Colombia. Hier werd een MRI gemaakt, die het beeld toonde zoals is te zien in figuur 2. De ouders kregen te horen dat er maar één mogelijkheid was qua behandeling, namelijk een hemisferotomie links, met als consequentie een hemiparese rechts. Wat ik later van de ouders begreep kregen ze verder geen uitleg en/of counseling. De behandeling met deze consequenties werd door de ouders afgewezen.

Vanwege verdere achteruitgang van het kind, zowel qua aanvallen (voortdurend kleine aanvallen met staren en een tonische component) als leervermogen en gedrag, is het uiteindelijk op verzoek van de kinderarts gelukt het meisje met spoed voor verdere diagnostiek en behandeling naar Kempenhaeghe te verwijzen (normaliter zit tussen een aanvraag en de uiteindelijke verwijzing naar het buitenland vanuit Aruba ongeveer vier maanden, bij dit meisje is het in vier dagen gelukt). Ze kreeg hier na één dag een EEG-videomonitoring die bij opstarten (het kind sliep)
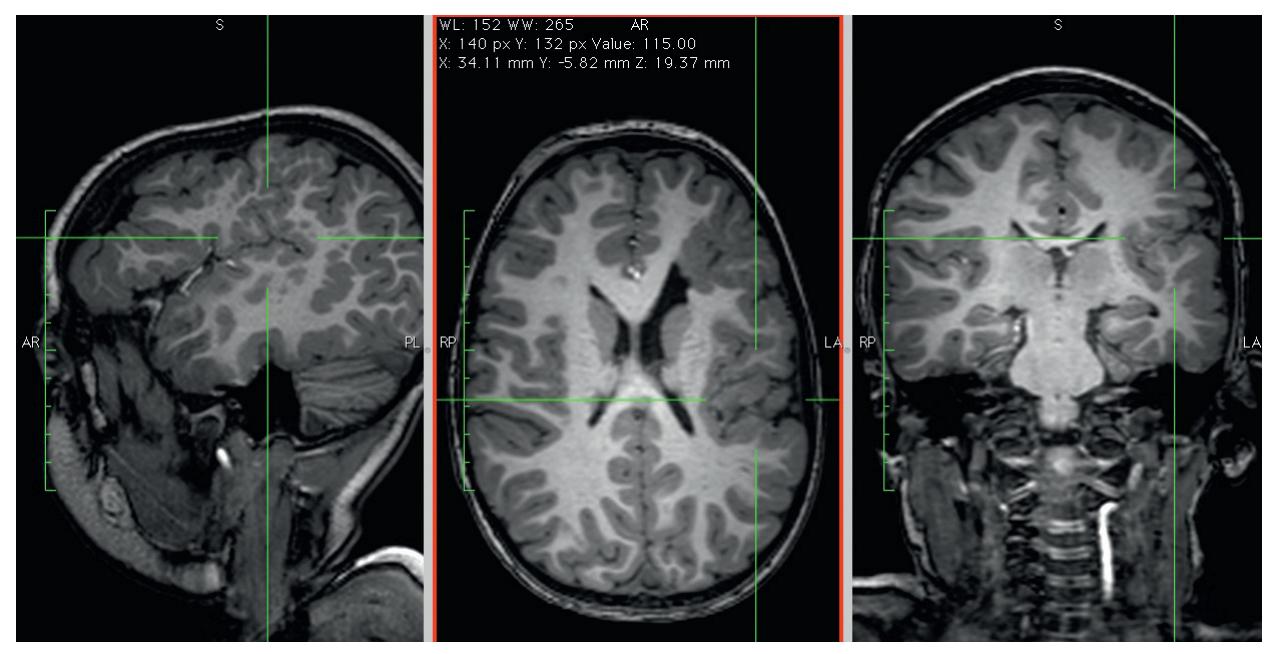

Figuur 2 MRI met beeld van een grote ontwikkelingsstoornis in de linker hemisfeer, met links frontaal een schizencefalie en verder in vrijwel de gehele hemisfeer uitgebreide polymicrogyrie en waarschijnlijk ook corticale dysplasie. 